\title{
The Economic Phenomenon Behind the Education in China, and the Development Prospects and Suggestions for Vocational Education in China
}

\author{
Rui Gan* \\ University of Bristol, Senate House, Tyndall Ave, Bristol BS8 1TH, United Kingdom \\ *Corresponding author: Rui Gan, ganruigr@163.com
}

\begin{abstract}
This article analyzes the education system and its current situation in China. It has been pointed out that the examoriented education with the college entrance examination as its main content leads to the scarcity of high-quality educational resources and the unfair distribution of educational resources. It also leads to the economic phenomenon where parents, schools, students, and other education-related industry chains are engaged in a fierce competition for educational opportunities. In addition, this article also points out the strategic significance of vocational education for China's future talent development in addition to the national policy support for vocational education. In conclusion, the future development of vocational education is bright and of great significance to China's education system.
\end{abstract}

Keywords: Development; Economy; Education; Vocational education

Publication date: September 2021; Online publication: September 30, 2021

\section{Introduction}

The education in China is exam-oriented and is represented by the college entrance examination (CEE). For a long time, "inferior" prejudice has seriously restricted the development of vocational education. There exists an idea that has been deeply rooted, where if a student is unable to learn in high school, he or she will be sent for vocational secondary education, and in the same way, if a student is unable to move on into a university, he or she will be sent for higher vocational education ${ }^{[6]}$. However, China today has begun to develop and attach importance to vocational education, allowing students to enter senior middle schools or vocational secondary schools based on their own interests and directions for future development after the completion of junior middle school. The educational policy of talent transfer can be understood as the transformation of China's education from a competitive talent selection system to a new system of classifying academic talents and skilled talents to cultivate as well as utilize talents effectively ${ }^{[7]}$. Therefore, according to the market law of economics, this article analyzes China's education system and its current situation, describes the rise and development prospects of vocational education, and finally provides suggestions for vocational education.

\section{China's education system and its current situation}

China's current education system is exam-oriented, and it is represented by the CEE. According to the Education Law of the People's Republic of China, the education system in China comprises of preschool education (kindergarten), primary education (primary school), secondary education (junior middle school and senior middle school), and higher education (university) ${ }^{[8]}$. In 1977, China restored the CEE, and over the past 44 years, the CEE has brought many talents to China and changed the fate of countless ordinary 
people. Therefore, the slogan, "knowledge changes destiny," has been deeply embedded in the souls of the Chinese people ${ }^{[6]}$. In addition, unlike the "certificate system" that allows senior middle school students in the United Kingdom (UK) to enter universities ${ }^{[5]}$, China's CEE system is of "one chance only," which means students can only take the CEE once after completing senior middle school, and in the context if they fail, they have to wait until the following year to retake the test, which would add an extra year ${ }^{[4]}$. Therefore, the existence of the exam-oriented education also means that students have go through the fierce competition of CEE in order to obtain an opportunity to enter their ideal universities.

The scarcity of high-quality educational resources and the unfair distribution of educational resources describe the current situation of China's education. Since the CEE is a fair selection test, it has become a narrow bridge for many families and students. Statistics have shown that in $2020^{[12]}$, there were 537,100 schools of all kinds and at all levels, with 289 million students in China. Among them, 14,200 were senior middle schools with 24.9445 million students, while 9,865 were vocational secondary schools with 16.2814 million students. In addition, the number of applicants for China's College Entrance Examination in 2021 was 10.78 million, which was 70,000 more than the previous year; it is a number that has been rising year by year ${ }^{[11]}$. The importance and cruelty of the CEE along with the vast population and number of school students in China have contributed to the fierce competition in its education. Students, parents, schools, and the whole education-related industry chain compete for educational opportunities, reflecting the scarcity of high-quality educational resources. In relation to that, the shortage of high-quality resources results in the unfair distribution of educational resources ${ }^{[17]}$. For example, students who are in excellent primary and junior high schools have the opportunity to continue in well-known senior middle schools. This leads to the increase in demand for housings near well-known schools under the principle of "nearby enrolment," thus leading to a rise in housing prices ${ }^{[3]}$. After the commencement at these well-known senior middle schools, students would still have to study hard to enter their ideal universities. This has led to the establishment of a large number of curriculum training institutions and the rise of the cost of family education. It is precisely because of the provision of better educational opportunities, such as purchasing houses nearby the schools and hiring training institutions, by wealthy families for their children which leads to the unfair distribution of educational resources.

\section{The rise of vocational education in China}

Vocational education mandates educators to obtain the vocational knowledge, skills, and professional ethics required by a particular occupation or productive labor. Vocational education often plays a vital role in cultivating high-quality workers and skilled personnel in the frontline of production and service ${ }^{[2]}$. It is of great practical significance to develop characteristic vocational education as well as strengthen theoretical and practical research on vocational education for the development and prosperity of the economy. China has introduced a series of policies to promote the sustainable development of vocational education. Since the reform and opening-up, vocational education has provided strong talent and intelligence support for economic and social development. The basic framework of a modern vocational education system has been established. Its ability to serve economic and social development as well as its social appeal have been growing. Since the 18th National Congress of the Communist Party of China, the industrial structure in China has entered a stage of further adjustment, and the demand for skilled workers is bound to keep increasing. With the continuous growth of market demand, the employment rate of vocational education graduates has exceeded that of undergraduates, and the national support for the development of vocational education is also increasing. As China has entered a new stage of development as well as accelerated industrial upgrading and economic restructuring, there is an increasingly urgent need for skilled personnel from all walks of life; thus, vocational education is playing an increasingly important role ${ }^{[14]}$. 


\section{China's support for vocational education}

The development of vocational education reflects the level of national economic development and educational modernization. Since the 18th National Congress of the Communist Party of China (CPC), and especially since The State Council promulgated the National Plan for the Implementation of Vocational Education Reform, the reform and development of China's vocational education have entered the fast track of improving the quality, adding value, and enhancing capacity; thus, the pattern of vocational education has changed.

In response to this misunderstanding, the National Plan for the Implementation of Vocational Education Reform clearly pointed out at the beginning that vocational education and general education are two different types of education, which are equally important.

According to statistics from the Ministry of Education ${ }^{[1]}$, more than 3 million students were enrolled in the national vocational classified examination in 2020, accounting for more than $60 \%$ of the total enrolment in vocational schools, easing the anxiety of "thousands of troops crossing a single log bridge" and promoting the optimization of the educational structure. At present, China has 11,300 vocational schools with 30.88 million students. China has established the world's most extensive vocational education system, training many skilled personnel for economic and social development.

\section{Future of vocational education}

From January to July 2021, China introduced several policies to promote the development of vocational education, with one issued almost every month. Therefore, with the development and transformation of the industry, the importance of vocational education is increasingly prominent. A series of policies in China emphasizes the importance of vocational education in hope to promote its further development.

The enrolment expansion of higher vocational education and the corresponding higher vocational exam have effectively supported vocational education. They are the keys to the success of vocational education and the cornerstones of the future. The students in vocational secondary schools can enter the same universities as senior middle school students through higher vocational enrolment expansion and the corresponding higher vocational examination (HVE). With the emphasis on talent education in China, it has become a trend to expand the enrolment of colleges and universities ${ }^{[10]}$. However, due to the influence of the 44-year-old CEE, it has been widely believed that by only attending senior middle schools, students may have the chance to enter universities ${ }^{[6]}$. Going to college was rare in the mid-1990s. From 1999 to 2010, college enrolment expanded significantly for more than a decade, and the students from vocational secondary schools gained many learning opportunities. The HVE, which corresponds to the CEE, allows students to enter college. The expansion of higher vocational education and the corresponding HVE also indicate that the CEE is no longer a narrow bridge for students to step into universities; students from senior vocational schools also have the opportunity to study. It is worth mentioning that the CEE focuses on the test of culture, whereas HVE is a test of culture and professional skills. In terms of their difficulties, the HVE is more accessible than the CEE, which makes the examination environment for students from senior middle schools and vocational secondary schools fairer ${ }^{[9]}$.

The reduction of vocational education costs is conducive to the demographic dividend under the threechild policy ${ }^{[16]}$. The reduction of tuition fees for vocational education in China demarcates the importance of vocational education and its bright prospects for the future. In order to improve its population structure and maintain its advantage in human resources, China has implemented the three-child policy, which allows couples to have up to three children. Today, however, the competition and high cost of education are preventing young people from having children. Therefore, China has adopted a series of welfare policies for vocational education, such as policy publicity, diverting students, and lowering tuition fees, so that the prejudice of people toward vocational education can be eliminated rather than competing fiercely in the 
college entrance examination. In addition, the subsidies provided by China for the cost of vocational education cease the worries of parents in regard to the high cost of education, thus boosting fertility rates. Therefore, the series of support for vocational education also reflects the importance of vocational education for China's future development. This indicates that the future development of vocational education in China is bright.

The double reduction policy guarantees the number of students in vocational education in the future. This policy is to reduce the burden of homework and extracurricular training for students. In March 2021, the Ministry of Education proposed that the proportion of vocational secondary school students and senior middle school students should be roughly equal, meaning that only about $50 \%$ of students would be able to enter senior middle schools in the future ${ }^{[13]}$. In the past, parents had thought that only students with poor grades, who could not enter senior middle schools, would be sent to vocational secondary schools. This is because senior middle schools had grade requirements, whereas vocational secondary schools did not. With the increasing number of students entering vocational secondary schools, many parents begin to seek remedial classes when their children are in junior middle schools to improve their academic performance to be enrolled in senior middle schools. The emergence of the double reduction policy is to avoid such a situation. Therefore, while reducing the academic burden of students and the financial burden of parents, the policy also provides a guarantee for the future number of students in vocational education.

In this way, China's determination to develop vocational education is evident. China has made great efforts to enhance the adaptability of vocational and technical education, including highlighting the characteristics of vocational education, improving top-level design, creating a credible model to run schools, and improving the quality of education.

\section{Suggestions for the development of vocational education}

A standardized scoring mechanism should be established for vocational education. There are still several problems with the vocational education in China, such as flawed system construction and standards, imperfect construction of vocational skill training bases, insufficient motivation for enterprises to participate in running schools, and uneven quality of school-running and personnel training. Therefore, China should establish a standard set of national vocational education scoring system so that more vocational schools would be able to recognize their deficiencies, thus making targeted improvements. By improving the school quality supervision and evaluation mechanism, the critical role of social impetus in the development of vocational education is in the construction of a high-quality professional management team in order to activate the vitality of career development.

A first-class model university should be built to enhance students' sense of honor and social recognition of vocational education. Nearly $50 \%$ of respondents had an average or poor impression toward vocational school students. Data have shown that the overall status of vocational students as excellent, good, fair, poor, and unclear is $21.14 \%, 31.42 \%, 38.65 \%, 5.79 \%$, and $3.00 \%$, respectively ${ }^{[15]}$. It can be seen that the current situation of vocational students or the overall impression of nearly $50 \%$ of people is insufficient. Millions of Chinese students would study for many years to pass the college entrance exam in order to be accepted by their ideal universities. Therefore, China should take the lead in building several first-class vocational schools and train up outstanding students to improve their sense of honor and belonging as well as the recognition of vocational education. Similar to a Chinese saying, "the rich will drive the rich"; thus, only when top schools have succeeded, then vocational education can be recognized, and other schools would have a chance to develop.

The ability to develop vocational education services should be improved. There is a close relationship between vocational education and the development of the economy as well as the society. At present, the Chinese economy has shifted from a rapid growth stage to a high-quality development stage. As an essential 
supply-side to support the economic development, vocational education needs to actively seek changes and adapt to the needs of economic transformation with high-quality development. At the same time, with the acceleration of economic globalization and the expansion of international cooperation on production capacity, China should strive to improve the capacity of vocational education to serve international cooperation in regard to production capacity, promote their vocational education to the world, and contribute the Chinese wisdom, Chinese experience, and Chinese solutions.

\section{Conclusion}

Due to China's education system and its current situation, today's college entrance examination has led to the lack of high-quality educational resources and the unfair distribution of educational resources. In order to break this vicious circle, the state has given a series of policy support to vocational education. In the future, vocational education would be guaranteed under the double reduction policy, and the demographic dividend under the three-child policy will also be stimulated. The standardization of vocational education grading, the construction of first-class vocational universities, and the improvement of vocational education services would bring a leap forward in the development of vocational education and provide strong support in the complete construction of socialist modernization in China.

\section{Disclosure statement}

The author declares that there is no conflict of interest.

\section{References}

[1] Xiaoxiang Morning News, 2021, Xinhuanet: China's Vocational Education Reform and Development Achievements Overview. Xiaoxiang Morning News Official Hundreds. https://baijiahao.baidu.com/s?id=1696825827617884665\&wfr=spider\&for $=$ pc (accessed on August 10, 2021).

[2] Billett S, 2011, Vocational Education: Purposes, Traditions and Prospects, Springer Science \& Business Media, 1-15.

[3] Burkhoff A, 2015, One Exam Determines One's Life: The 2014 Reforms to the Chinese National College Entrance Exam. Fordham Int'1 LJ, 38: 1473.

[4] Davey G, De Lian C, Higgins L, 2007, The University Entrance Examination System in China. Journal of Further and Higher Education, 31(4): 385-396.

[5] Field K, 2013, Education, Education, Education: Reforming England's Schools. Professional Development in Education, 39(5): 865-866.

[6] Gu M, 2006, An Analysis of the Impact of Traditional Chinese Culture on Chinese Education. Frontiers of Education in China, 1(2): 169-190.

[7] Hao Y, 2012, The Reform and Modernization of Vocational Education and Training in China (No. SP III 2012-304). WZB Discussion Paper.

[8] Hayhoe R, 2019, Contemporary Chinese Education, Routledge, 6-19.

[9] Sichuan Provincial Department of Education, 2016, Sichuan Has Made Great Efforts to Develop Secondary Vocational Education. Ministry of Education of the People's Republic of China. http://www.moe.gov.cn/jyb_xwfb/s6192/s222/moe_1755/201607/t20160701_270359.html (accessed on August 5, 2021). 
[10] CCTV Network, 2020, Ministry of Education: China Will Enroll 3 Million More People in Vocational Education Over the Next Three Years. Ministry of Education of the People's Republic of China. http://www.moe.gov.cn/fbh/live/2020/52735/mtbd/202012/t20201209_504278.html (accessed on August 5, 2021).

[11] China Youth Daily, 2021, A Total of 10.78 Million People Applied for the National College Entrance Examination in 2021. Ministry of Education of the People's Republic of China. http://www.moe.gov.cn/jyb_xwfb/xw_zt/moe_357/2021/2021_zt12/meiti/202106/t20210603_535277 .html (accessed on August 5, 2021).

[12] Development Planning Department, 2021, Main Results of National Education Statistics in 2020. Ministry of Education of the People's Republic of China. http://www.moe.gov.cn/jyb_xwfb/gzdt_gzdt/s5987/202103/t20210301_516062.html (accessed on August 5, 2021).

[13] Tencent, 2021, The Ministry of Education Attaches Great Importance to Double Reduction Policy, High School Entrance Examination Shunts One Size Fits All, Vocational Education or Become the Next Tuyere. https://new.qq.com/omn/20210731/20210731A08TYD00.html (accessed on August 5, 2021).

[14] Wang L, Jiang D, 2013, Chinese Vocational Education: Borrowing and Reforming: An Interview with Professor Dayuan Jiang, MOE Research Fellow. Chinese Education \& Society, 46(4): 92-99.

[15] Sichuan Vocational Education, 2021, Nearly 50 Percent of People's Impression of Vocational School Students Is Average or Below? A Table to Understand the Connotation of Vocational Schools!. Wechat Official Account. https://mp.weixin.qq.com/s/5lbA8Uzxp4v5MAb1TO6ipQ (accessed on August 5, 2021).

[16] Xinhua News Agency, 2021, Decision on Optimizing the Family Planning Policy to Promote LongTerm Balanced Population Development. Xinhuanet. http://www.xinhuanet.com/politics/zywj/2021 07/20/c_1127675462.htm?baike (accessed on August 5, 2021).

[17] You Y, 2007, A Deep Reflection on the "Key School System" in Basic Education in China. Frontiers of Education in China, 2(2): 229-239. 